\title{
Plasma Luminescence feedback control system for precise ultrashort pulse laser tissue ablation
}

\author{
B.-M. Kim, M. D. Feit, A. M. Rubenchik,
} D. M. Gold, C. B. Darrow, and L. B. Da Silva

This paper was prepared for and presented at the SPIE International Symposium on BiOS ' 98

International Biomedical Optics

San Jose, California

January 24-30, 1998

January 1, 1998

This is a preprint of a paper intended for publication in a journal or proceedings. Since changes may be made before publication, this preprint is made available with the understanding that it will not be cited or reproduced without the permission of the author. 


\section{DISCLAIMER}

This document was prepared as an account of work sponsored by an agency of the United States Government. Neither the United States Government nor the University of California nor any of their employees, makes any warranty, express or implied, or assumes any legal liability or responsibility for the accuracy, completeness, or usefulness of any information, apparatus, product, or process disclosed, or represents that its use would not infringe privately owned rights. Reference herein to any specific commercial product, process, or service by trade name, trademark, manufacturer, or otherwise, does not necessarily constitute or imply its endorsement, recommendation, or favoring by the United States Government or the University of California. The views and opinions of authors expressed herein do not necessarily state or reflect those of the United States Government or the University of California, and shall not be used for advertising or product endorsement purposes. 


\title{
Plasma luminescence feedback control system for precise ultrashort pulse laser tissue ablation
}

\author{
B.-M. Kim, M. D. Fcit, A. M. Rubenchik, D. M. Gold, C. B. Darrow, L. B. Da Silva \\ Lawrence Livermore National Laboratory \\ Livermore, CA, 94550
}

\begin{abstract}
Plasma luminescence spectroscopy was used for precise ablation of bone tissue without damaging nearby soft tissue using ultrashort pulse laser (USPL). Strong contrast of the luminescence spectra between bone marrow and spinal cord provided the real time feedback control so that only bone tissue can be selectively ablated while preserving the spinal cord.
\end{abstract}

Keywords : ultrashort pulse laser, plasma, luminescence spectroscopy, feedback control

\section{INTRODUCTION}

As lasers are accepted as possible replacement for conventional surgical tools in many medical fields, a focus of research has been on more effectively removing the biological tissues while reducing mechanical/thermal damage to the surrounding tissues. Recently, many studies have shown that ultrashort pulse lasers $(<1 \mathrm{ps})$ can meet this need ${ }^{1-6}$. In this short pulse domain, the ablation process is distinguished from the conventional longer pulse ablation which mostly depends on the photothermal heating in the media. As the pulse width becomes shorter, multiphoton ionization dominates during the ablation process which leads to the plasma optical breakdown. The plasma is ejected at a rate $\sim 10^{7} \mathrm{~cm} / \mathrm{s}$ which is faster than the shockwave speed $\sim 10^{6} \mathrm{~cm} / \mathrm{s}$ and the even slower heat diffusion. Therefore, the mechanical/thermal damage is minimized with these short pulses. Additionally, since the plasma is highly reflective and absorptive, for longer pulses such as $1 \mathrm{~ns}$ pulses, a large fraction of the incoming energy is reflected back or channeled into plasma heating instead of being absorbed by the tissue and used for tissue removal. On the other hand, the energy deposition time for ultrashort pulses is much shorter than the plasma expansion time and therefore the ablation is highly effective $(\sim 1 \mu \mathrm{m} /$ pulse $)$ in terms of energy consumption ${ }^{2}$.

Luminescence is generated from a high temperature plasma during ablation. Strong luminescence signals for calcium based plaque in atherosclerotic tissue has been reported ${ }^{7-9}$. Our studies are focused on a feasibility test of using the luminescence spectroscopy as a tool for optical feedback during micro-spinal surgery where the calcium based bone tissue needs to be removed while preserving the soft nerve tissue which stems from the spinal cord. The results suggest that the hard tissue can be selectively ablated with high accuracy.

\section{RESULTS AND DISCUSSIONS}

Our ultrashort pulse laser ablation system is equipped with four separate lasers. An $82 \mathrm{MHz}$ TiSapphire actively mode-locked laser (Spectra Physics, Model \# 3960) is pumped by a 5 W, frequency doubled Nd:YAG laser (Spectra Physics Model : Millenia) running at $532 \mathrm{~nm}$. The mode-locked laser pulse has duration of $100 \mathrm{fs}$ at $790 \mathrm{~nm}$. Its pulse is amplified by a Ti-Sapphire regenerative amplifier (Positive Light, Model : Spitfire) through a chirped pulse amplification (CPA) process. This amplifier is pumped by a $10 \mathrm{~W}, 527 \mathrm{~nm}$ Nd:YLF laser (Positive Light, Model : Merlin). The final pulse duration is about $150 \mathrm{fs}$ running at $1 \mathrm{kHz}$ and its amplified energy 
is more than $1 \mathrm{~mJ} /$ pulse at $790 \mathrm{~nm}$. The ablation rate is approximately $1 \mathrm{~mm} / \mathrm{s}$ using a $1 \mathrm{kHz}$ beam train. The focused beam size was less than $150 \mu \mathrm{m}$ with TEM $_{00}$ mode.

A fresh porcine spine was frozen and cut transversely to expose the bone marrow and spinal cord. The cross section was cleaned with a soft brush to remove the debris of the soft tissue left in the bone marrow during cutting. The laser pulses were focused onto the cross sections of spinal cord and bone marrow to generate the plasma luminescence.

The luminescence signal was collected by a $1 \mathrm{~mm}$ diameter optical fiber and was delivered to the spectrometer and charge coupled device (CCD) camera. The source light was normally incident onto the tissue and the fiber was placed $20^{\circ}$ from the normal direction and $5 \mathrm{~mm}$ away from the tissue surface. A mechanical shutter for the source laser and a CCD shutter were controlled by a pulse generator. Fig. 1 shows the luminescence spectra from both bone and spinal cord. As seen from the figure, not only the overall luminescence intensity is strong but strong calcium lines are observed from the bone luminescence spectrum. On the other hand, the luminescence from the spinal cord is much smaller and there are no calcium line features.

The overall luminescence intensity decreases as the ablation front moves deeper into the ablation hole because less ablated material is ejected and the distance between the ablation front and detector becomes larger as discussed in the previous study ${ }^{10}$. Fig. 2 shows the temporal changes of the absolute luminescence intensities integrated over each 100 shots during $1 \mathrm{sec}, 1 \mathrm{kHz}$ pulse train. As expected, the total intensity of luminescence decreases rapidly as the ablation front moves on deeper into the sample while the luminescence intensity does not vary significantly for spinal cord. After first 600 shots, the overall luminescence from spinal cord becomes stronger than that from the bone tissue. From this study, it was concluded that by comparing the luminescence ratio between $616 \mathrm{~nm}$ and $575 \mathrm{~nm}$, we can accurately discriminate the two tissue types better than comparing the absolute intensities. The luminescence ratio between the two wavelengths is consistent for both bone and spinal cord despite the fact that the absolute intensity of the bone changes dramatically during 1000 shots as shown in Fig. 3. The ratios between these two wavelengths $(616 \mathrm{~nm} / 575 \mathrm{~nm})$ were $4.8( \pm 1.06)$ for bone and $1.4( \pm 0.27)$ for spinal cord.

In a more practical setup as shown in Fig. 4, this beam was delivered and focused onto the tissue using an articulated arm which is composed of seven separate high damage threshold mirrors and one focusing lens. The luminescence signal was collected by a $200 \mu \mathrm{m}$ optical fiber which is attached on the handpiece of the articulated arm and connected to a $1 \times 2$ fiber coupler. This signal was detected by two photomultiplier tubes (PMT) which are equipped with $616 \mathrm{~nm}$ and $575 \mathrm{~nm}$ bandpass filters respectively. To remove the intense laser source light, an additional short wave pass filter with cut-off wavelength at $650 \mathrm{~nm}$ were added to each PMT's providing optical density of 7 for the source light. The typical luminescence signals for these two detectors are shown in Fig. 5(a) for bone and in Fig. 5(b) for spinal cord. The initial strong peak corresponds to the laser source light which is too strong to be filtered even by the OD 7 filters. Each detected signal was gated and integrated immediately after the strong laser signal so that only the plasma luminescence is collected. The integrated signal was compared in a computer and a TTL signal was generated to determine if the tissue is bone or spinal cord and to control the laser shutter. When the laser hit the spinal cord, the computer send an "off" signal to the mechanical shutter to close it. After the ablation stops, the shutter reopens after a short duration of $0.5 \mathrm{sec}$ so that the surgeon can keep ablating the bone.

Since luminescence spectroscopy requires a small fraction of the tissue to be ablated, it is of concern how to minimize the damage to the soft tissue. As mentioned earlier, the ablation rate for this short pulse width is approximately $1 \mu \mathrm{m} /$ pulse. The future goal of the study will focus on limiting the damage to less than $5 \mu \mathrm{m}$ which is believed to cause negligible damage to nerve tissue. To accomplish this, a fast electronics package is under development. Currently, the possible maximum damage is between $10-15 \mu \mathrm{m}$. 
SPIE-BiOS'98, Jan. 24 - 30, 1998, San Jose, CA Conference 3255, Applications of USPL in Med. and Biol.

\section{CONCLUSION}

We demonstrated that a safe and precise microsurgery system using ultrashort pulse laser is feasible. The two wavelength comparison technique provides accurate selective tissue ablation.

\section{ACKNOWLEDGMENTS}

This work was performed at Lawrence Livermore National Laboratory under the auspices of the U.S. Department of Energy under contract No. W-7405-ENG-48.

\section{REFERENCES}

1. B. C. Stuart, M. D. Feit, S. Herman, A. M. Rubenchik, B. W. Shore, and M. D. Perry, "Nanosecond-to-femtosecond laser-induced breakdown in dielectrics," Physical Review, 53, no. 4, pp. 1749-1761, 1996.

2. J. Neev, L. B. Da Silva, M. D. Feit, M. D. Perry, A. M. Rubenchik, and B. C. Stuart, "Ultrashort pulse lasers for hard tissue ablation," IEEE J. Selected Topics in Quantum Electronics, 2, no. 4, pp. 790-800, 1996.

3. A. A. Oracvsky, L. B. Da Silva, A. M. Rubenchik, M. D. Feit, M. E. Glinsky, M. D. Perry, B. M. Mammini, W. Small, and B. C. Stuart, "Plasma mediated ablation of biological tissues with nanosecond-to-femtosecond laser pulses: Relative role of linear and nonlinear absorption," IEEE J. Selected Topics in Quantum Electronics, 2, no. 4, pp. 801-809, 1996.

4. L. B. Da Silva, B. C. Stuart, P. M. Celliers, T. D. Chang, M. D. Feit, M. E. Glinsky, N. J. Heredia, S. Herman, S. M. Lane, R. A. London, D. L. Mattews, j. Neev, M. D. Perry, and A. M. Rubenchik, "Comparison of soft and hard tissue ablation with sub-ps and ns pulse lasers," SPIE Proceedings, 2681, pp. 196-200, 1996.

5. M. D. Feit, A. M. Rubenchik, B.-M. Kim, L. B. Da Silva, and M. D. Perry, "Physical characterization of ultrashort laser pulse drilling of biological tissue," Applied Surface Science, 1998, (in press)

6. R. Birngruber, C. A. Puloafito, A. Gawande, W.-Z. Lin, R. T. Schoenlein, and J. G. Fujimoto, "Femtosecond laser-tissue interaction: Retinal injury studies," IEEE J. Quantum Electronics, QE-23, no. 10, pp. 1836-1844, 1987.

7. A. A. Oraevsky, S. L. Jacques, G. H. Pettit, F. K. Tittle, and P. D. Henry, "XeCl laser ablation of atherosclerotic aorta," Lasers Surg. Med., 13, pp. 168-178, 1993.

8. L. I. Deckelbaum, J. J. Scott, M. L. Stetz, K. M. O'Brien, and G. Backer, "Detection of calcified atherosclerotic plaque by laser-induced plasma emission," Lasers Surg. Med., 12, pp. $18-24,1992$.

9. A. A. Oraevsky, R. O. Esenaliev, and V. S. Letokhov, "Temporal characteristics and mechanism of atherosclerotic tissue ablation by nanosecond and picosecond laser pulses," Lasers in the Life Sciences, 5, pp. 75-93, 1992.

10 B.-M. Kim, M. D. Feit, A. M. Rubenchik, B. M. Mammini, and L. B. Da Silva, "Optical feedback signal for ultrashort laser pulse ablation of tissue," Applied Surface Science, 1998 (in press) 


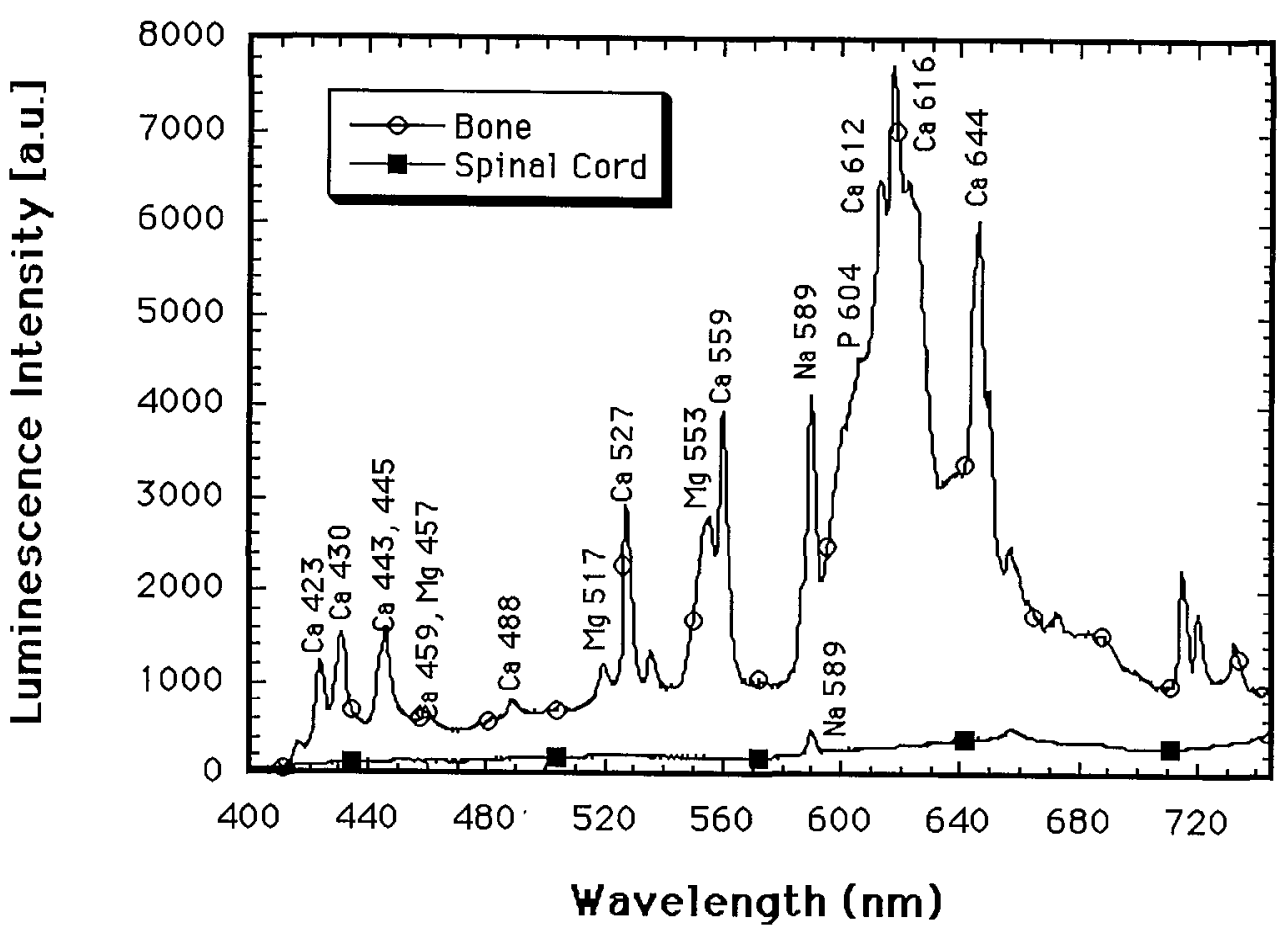

Fig. 1. Luminescence spectra from both porcine bone marrow and spinal cord. Strong calcium lines are observed from the bone spectrum.

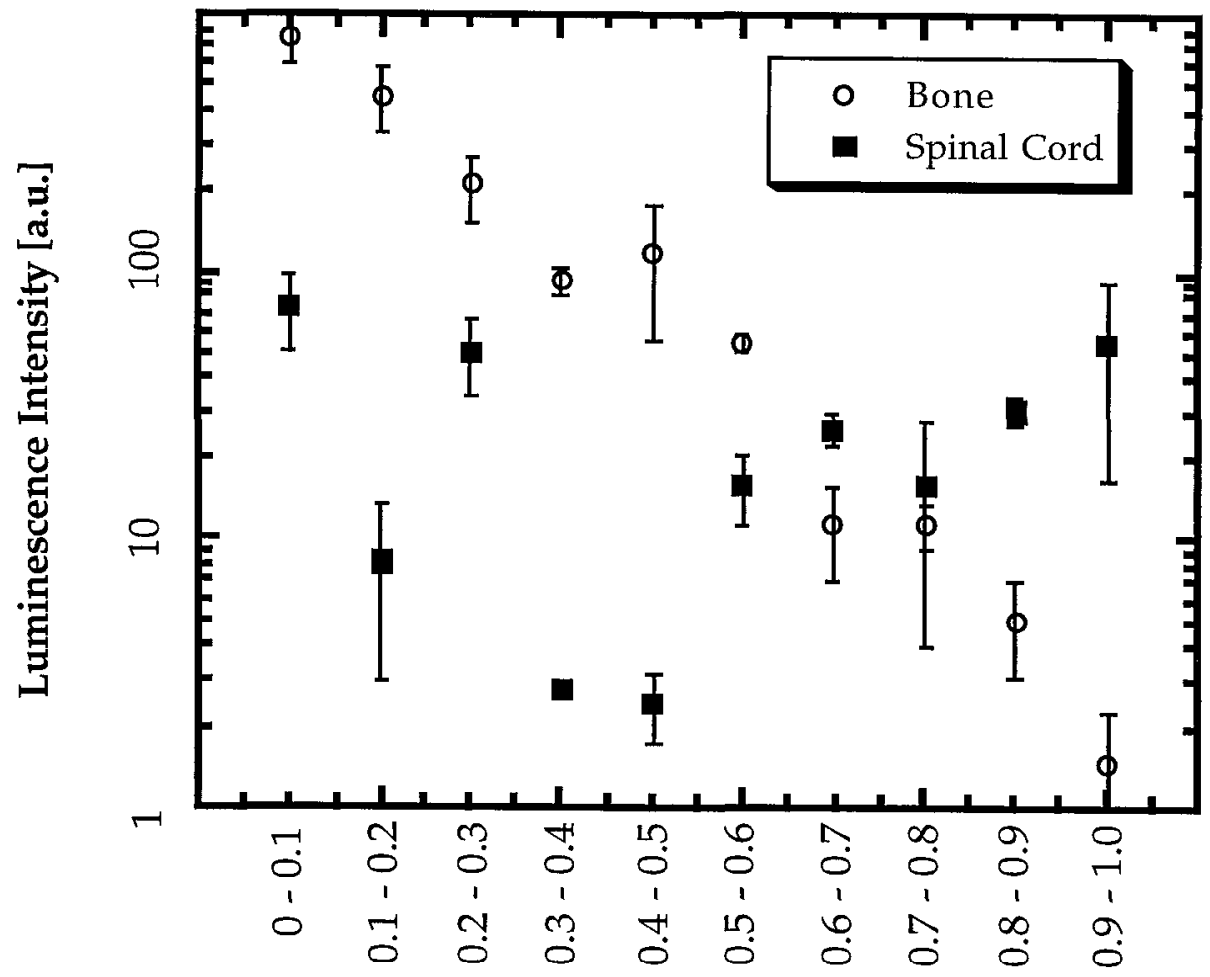

Interval (sec)

Fig. 2. Temporal changes of the absolute intensity of plasma luminescence from both bone and spinal cord. 
SPIE-BiOS'98, Jan. 24 - 30, 1998, San Jose, CA Conference 3255, Applications of USPL in Med. and Biol.

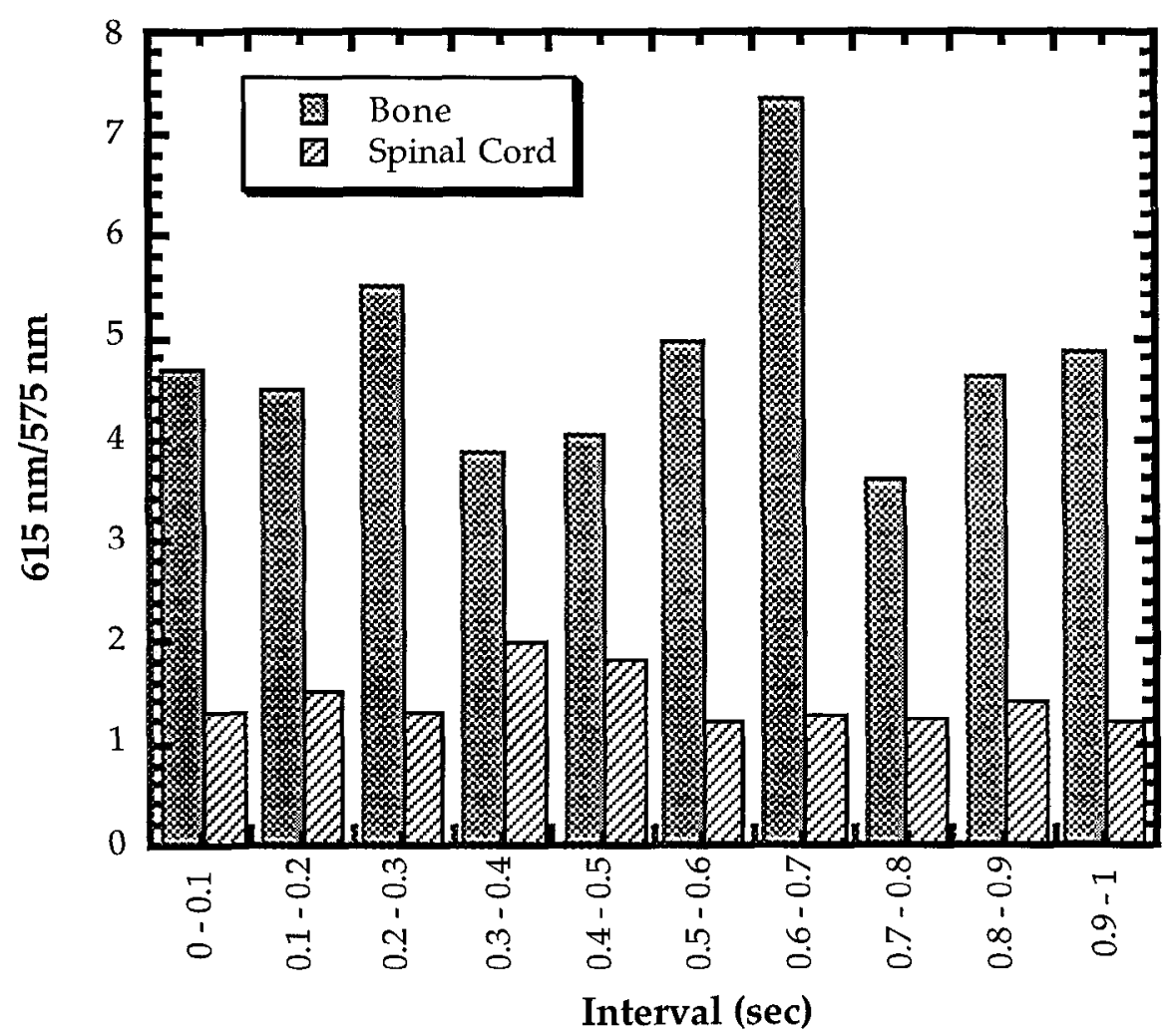

Fig. 3. Ratio of luminescence at $616 \mathrm{~nm}$ and $575 \mathrm{~nm}$ for both bone and spinal cord. Independent of absolute intensity, the ratio are consistent during $1 \mathrm{sec}, 1 \mathrm{kHz}$ pulse train.

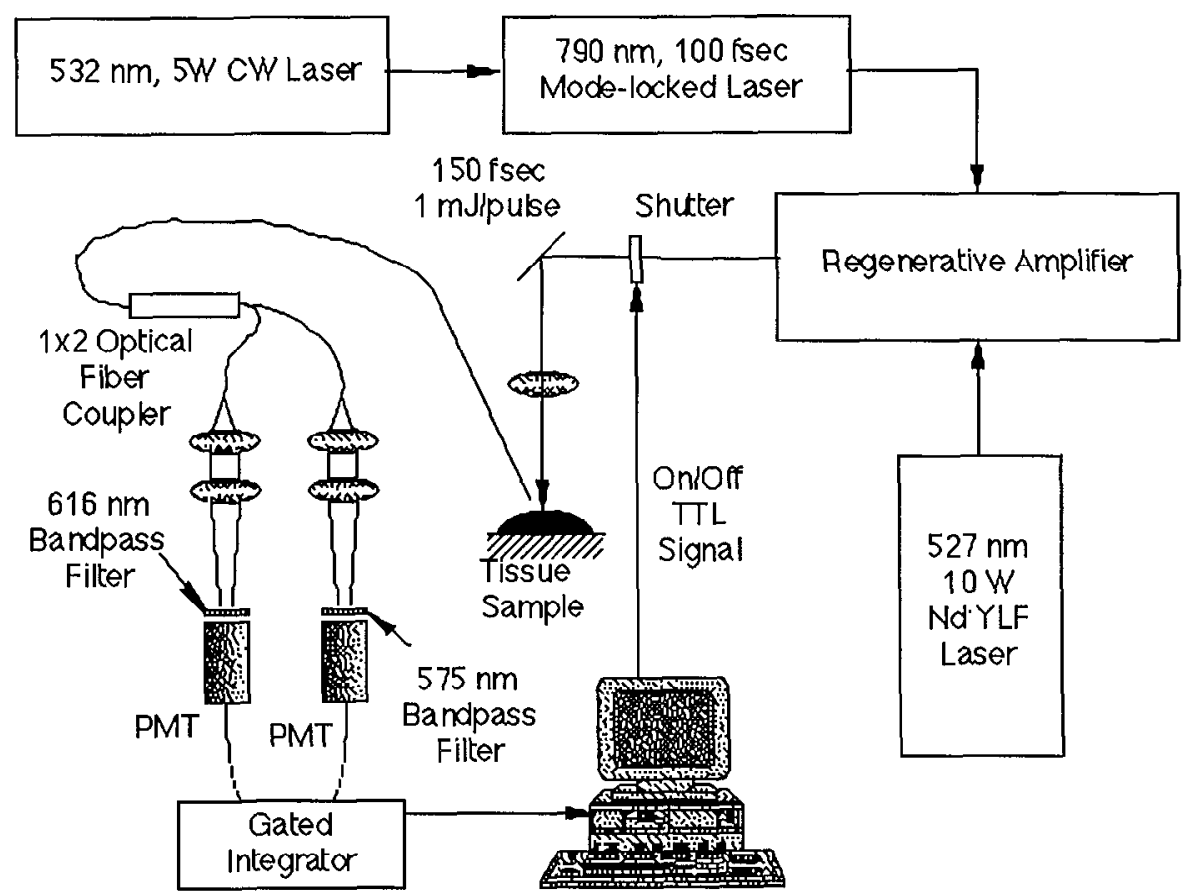

Fig. 4. A schematic for micro-spinal surgery using luminescence feedback control. 
SPIE-BiOS'98, Jan. 24 - 30, 1998, San Jose, CA Conference 3255, Applications of USPL in Med. and Biol.

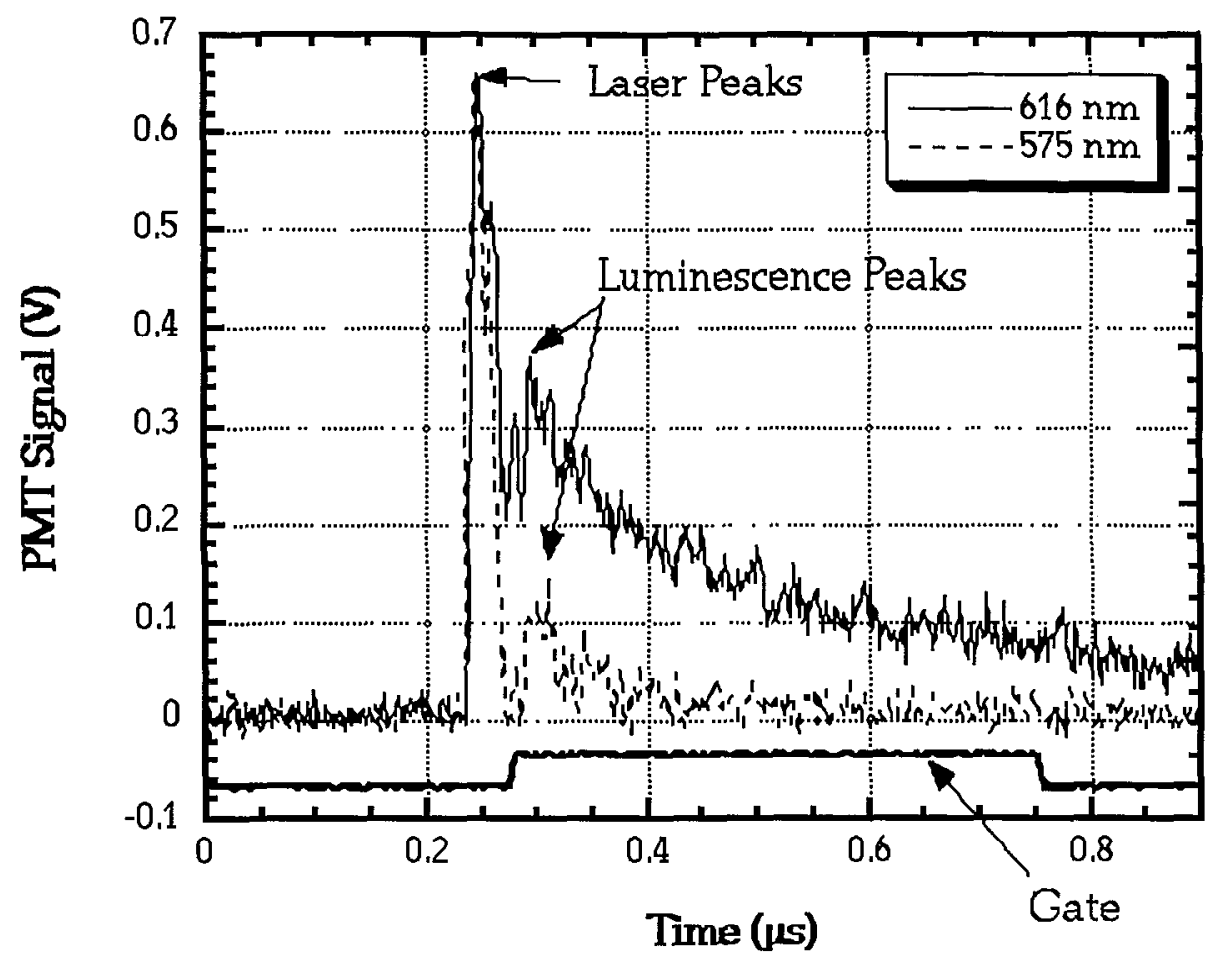

(a)

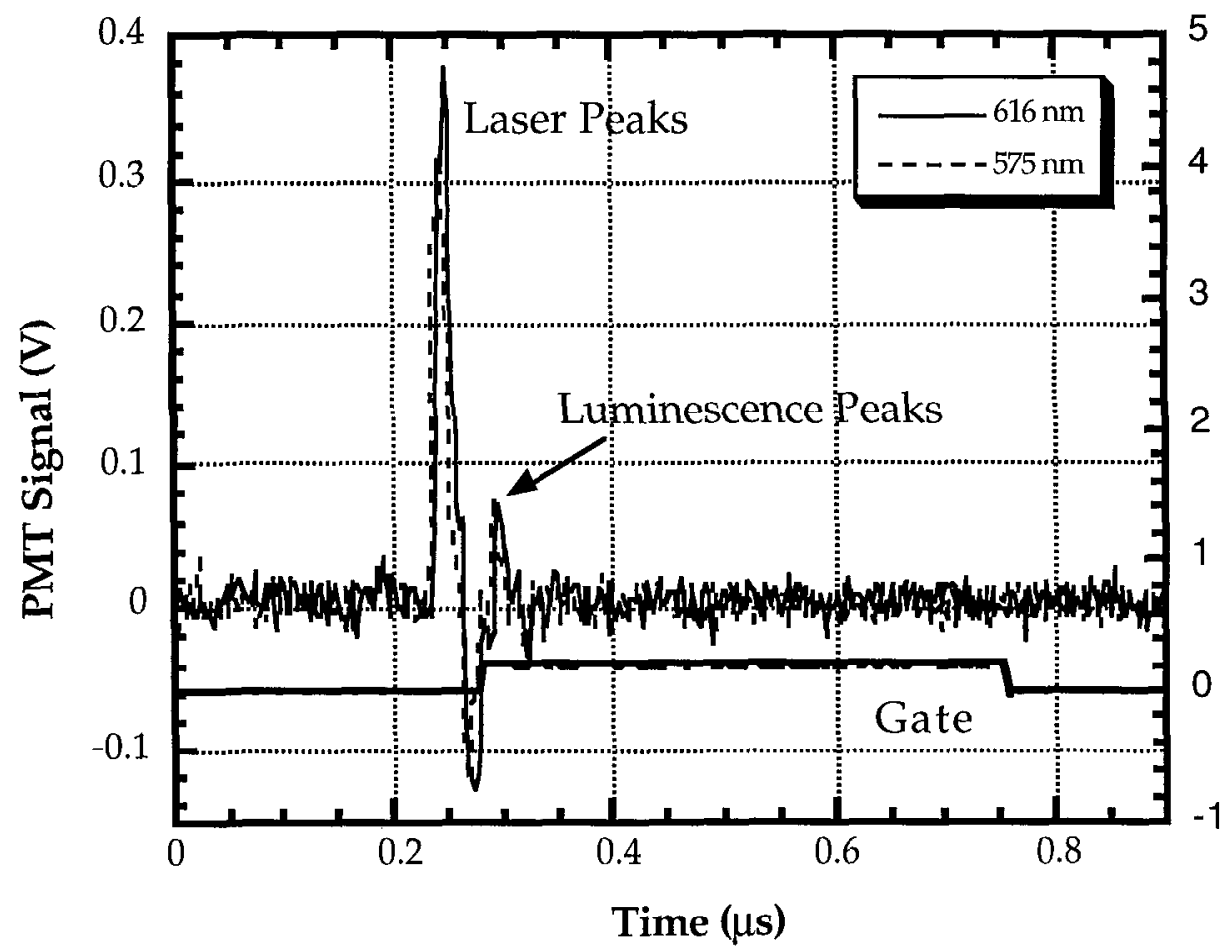

(b)

Fig. 5. Typical luminescence at $616 \mathrm{~nm}$ and $575 \mathrm{~nm}$ for (a) bone and (b) spinal cord. Initial strong peak represents the laser source light reflection. 


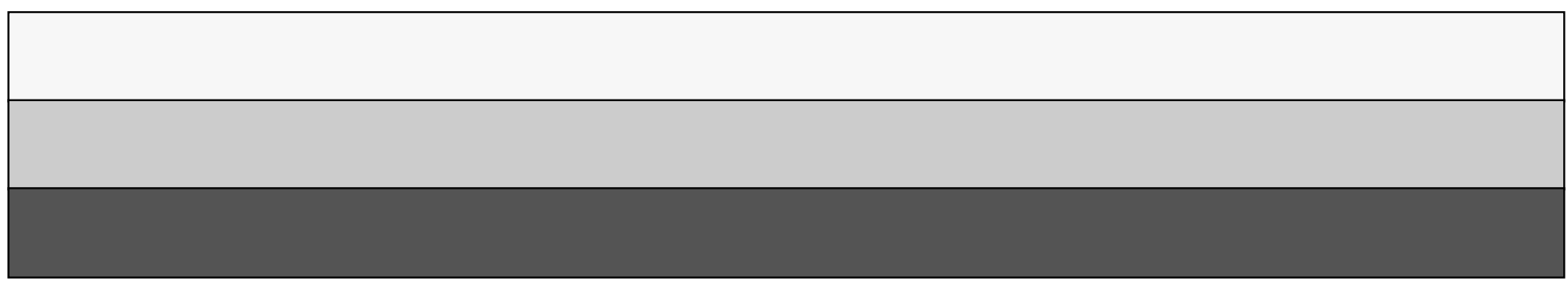

